\title{
ANÁLISE DE FALHA EM PLACA ÓSSEA ${ }^{1}$
}

\section{Resumo}

Os implantes ortopédicos podem falhar basicamente por três motivos: qualidade insatisfatória dos implantes, procedimento cirúrgico inadequado ou fatores inerentes ao paciente (forma de uso ou condições fisiológicas). A falha de um implante aumenta ainda mais o sofrimento de pessoas que tiveram que ser submetidas a um procedimento para colocação de uma prótese; e a subsequente recolocação (cirurgia de revisão) no caso de falha. Com intuito de verificar a ruptura de uma placa óssea em uso, uma análise do caso foi realizada. Para tanto se utilizaram as análises: visual, microestrutural, análise química por espectrometria ótica e análise da superfície de fratura em microscópio eletrônico de varredura. Essa placa faz parte de um sistema de fixação de fratura óssea do fêmur, constituído pela placa e parafusos fixadores que devem garantir que não haja movimento relativo entre as partes fraturadas do osso, promovendo a osteointegração do osso. A placa analisada apresentava dimensões de $290 \times$ $15,1 \times 4,6$ (comprimento $\times$ largura $\times$ espessura em milímetros) e 18 furos, que eram os locais de fixação dos parafusos junto ao osso. A fratura da placa ocorreu aproximadamente no meio da seção no sentido do comprimento, partindo de um local de contato entre um parafuso e um dos furos. No local de contato (furo-parafuso) também havia evidências de desgaste e produtos de corrosão. Os resultados das análises mostraram que a placa não apresentou problemas microestruturais nem de composição química. A ruptura ocorreu por fadiga incentivada por marcas de desgaste e o consequente processo de corrosão-desgaste gerado entre as duas superfícies de contato. Tal fato evidencia que houve movimento relativo entre os dois componentes, presumindo-se desta forma, que houve aperto insuficiente dos parafusos deixando a placa em balanço dentro do corpo favorecendo a nucleação de uma trinca e a consequente fratura.

Palavras-chave: Placa óssea; Análise de falha; Corrosão-desgaste; Fadiga.

\section{FAILURE ANALYSIS IN BONE PLATE}

\section{Abstract}

The orthopaedical implants can failure basically by three ways: undesirable quality of the implants, inadequate surgical procedure or factors associated to the patient (ways of use or physiological conditions). The failure of an implant still raises up the suffering of the people who was submitted to a procedure of placement of the prosthesis; and the following replacement (revision surgery) in the case of failure. With the interest to investigate the fracture of and bone plate in use, a failure analysis was performed. For that, it was utilized the following analysis: visual examination, microstructural evaluation, chemical analysis by optical spectrometry and analysis of the fracture surface in SEM. This plate is part of a system of femur fracture fixation, consisted by the plate and fixator screws which must guarantee that will not have relative movement between the fractured parts of the bone, providing the osseointegration. The analyzed plate presented dimensions of $290 \times 15,1 \times 4,6$ (length $\times$ width $\times$ thickness in millimeters) and 18 holes, which was the places of fixation along the bone. The fracture of the plate occurred approximately in the half of the length direction, starting from a contact between the screw and one of the holes. The place of the contact present (hole-screw) yet evidences of wear and corrosion products. The results of the analysis showed that the plate had not microstructural neither chemical composition problems. The fracture so occurred by fatigue stimulated by wear marks and the following process of wear corrosion generated between the surfaces. This fact make evident that there was relative movement in the components assuming therefore that had an insufficient grip of the screws leaving the plate unstable inside the body favoring the nucleation of a crack and following fracture.

Key words: Bone plate; Failure analysis; Wear corrosion; Fatigue.

1 Contribuição técnica ao $68^{\circ}$ Congresso Anual da ABM - Internacional, 30 de julho a 2 de agosto de 2013, Belo Horizonte, MG, Brasil.

2 Graduando, Eng. Metalúrgica, Universidade Federal do Rio Grande do Sul (UFRGS), Bolsista de Iniciação Científica do Laboratório de Metalurgia Física (LAMEF), grupo de Bioengenharia (BioEng), RS, Brasil.

3 Engenheiro de Materiais, Professor do Instituto Federal Sul-Riograndense (IFSUL), RS, Brasil.

4 Doutorando na área de concentração de Ciência e Tecnologia dos Materiais, PPGE3M, UFRGS, Analista Técnico, LAMEF, BioEng, RS, Brasil..

5 Dr. Engenharia, Coordenador do LAMEF, Professor Associado da UFRGS, RS, Brasil. 


\section{INTRODUÇÃO}

Um biomaterial, por definição, é qualquer material sintético que é usado para substituir ou restaurar a função de um tecido corporal e que está continuamente ou intermitentemente em contato com os fluidos corporais, como estabelece Davis. ${ }^{(1)}$

Com o desenvolvimento tecnológico dos materiais e a possibilidade de controlar as propriedades com maior precisão, atualmente existem representantes de várias classes de materiais no uso biomédico (cerâmicos, metálicos, polímeros, compósitos, entre outros).

Uma das áreas mais proeminentes de aplicação dos biomateriais é a ortopedia, com o intuito de restaurar ossos e articulações que sofreram trauma ou algum tipo de patologia. Considerando as propriedades das diferentes classes de materiais, os metais são, atualmente, os mais indicados para o suporte do peso do paciente. Segundo Davis, ${ }^{(1)}$ a maioria das cirurgias ortopédicas envolve a colocação de implantes metálicos e as principais ligas utilizadas são o aço inoxidável, o titânio puro e suas ligas e ligas em base cobalto.

As ligas em base titânio e titânio comercialmente puro são largamente utilizadas como biomateriais devido à sua alta resistência à corrosão e mecânica. Além disso, é um material inerte no ambiente corporal, não apresentando reações adversas.

As ligas em base cobalto são bastante utilizadas em cirurgias ortopédicas, tanto pela sua resistência à corrosão, quanto pelas suas propriedades mecânicas.

Os aços inoxidáveis são populares em aplicações biomédicas, especialmente na rede pública de saúde, por serem relativamente baratos quando comparados às outras ligas biomédicas. $\mathrm{O}$ aço inox, especificamente o austenítico, apresenta uma resistência à corrosão apreciável para solicitação em ambientes corrosivos (como por exemplo no interior do corpo humano), possibilidade de ser conformado e usinado por técnicas convencionais e ter propriedades mecânicas controláveis, entre elas resistência e ductilidade.

Conforme Davis, ${ }^{(1)}$ aços inoxidáveis usados em implantes devem estar adequados para um contato próximo e prolongado com o tecido humano, onde há condições ambientais que podem degradar o material. Os requisitos específicos para fabricação de um implante estão presentes em normas específicas para biomateriais. Essas normas, que são organizadas por órgãos internacionais e nacionais definem aspectos e métodos de caracterização de material, acabamento superficial, ensaios para qualificação de produto entre outros.

O não seguimento dos requisitos apresentados pelas normas pode oferecer risco de falha ou um potencializador de falha causada por algum motivo relacionado à inconformidade. Como exemplo, o acabamento superficial inadequado e uma microestrutura grosseira podem reduzir consideravelmente a resistência à fadiga de um componente. Diante disso enfatiza-se a necessidade e importância do seguimento dos requisitos de normas durante a fabricação de produtos biomédicos. A proposição desse trabalho é realizar a análise de falha de um implante que apresentou fratura durante o uso, empregando as normas recomendadas para a fabricação deste componente, juntamente com embasamento teórico disponível na literatura, para apontar a possível causa da falha. 


\section{MATERIAL E MÉTODOS}

O componente de estudo envolve a falha de um dispositivo de fixação interna, o qual é utilizado para manter a forma do osso reconstruído naturalmente ou, em cirurgia ortopédica corretiva, para estabilizar cortes e realinhamentos de ossos. Se trata de uma placa retangular de dimensões $290 \times 15,1 \times$ 4,6 (comprimento x largura x altura, em milímetros) que apresenta 18 furos onde os parafusos são fixados entre a placa e os fragmentos do osso fraturado, promovendo a estabilização do mesmo.

A Figura 1 mostra, de forma esquemática, alguns modelos de componentes e parafusos disponíveis no mercado; e uma simulação da prótese quando implantada no corpo para reconstrução óssea.
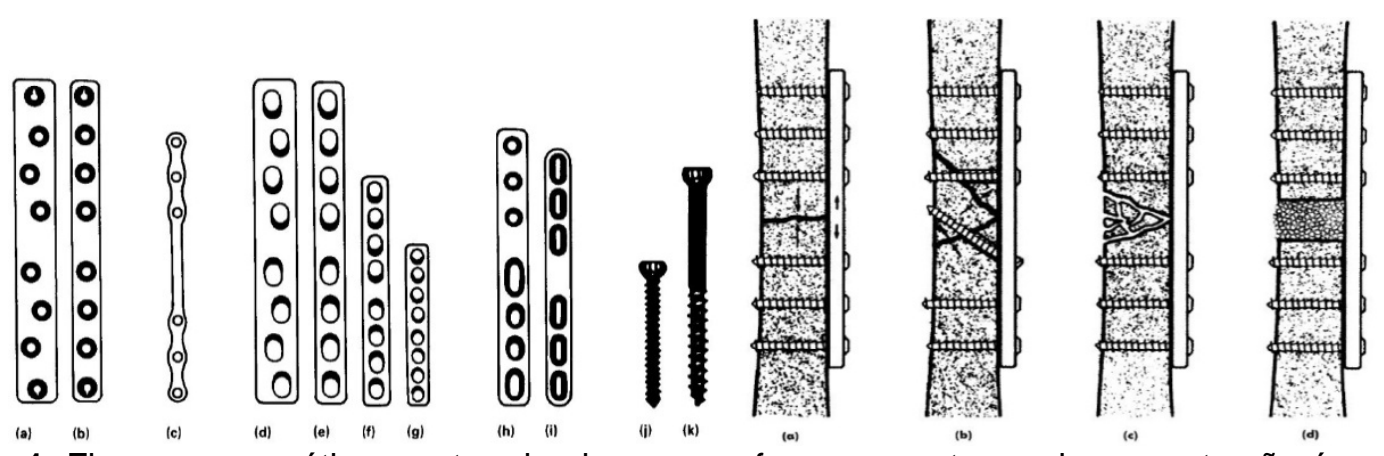

Figura 1. Figura esquemática mostrando placas, parafusos e as etapas da reconstrução óssea com auxílio de uma placa. ${ }^{(1)}$

O componente em questão, fabricado a partir de aço inoxidável austenítico, fraturou no sétimo furo (a fratura ocorreu em somente um dos lados) da esquerda para a direita, conforme mostra a Figura 2.

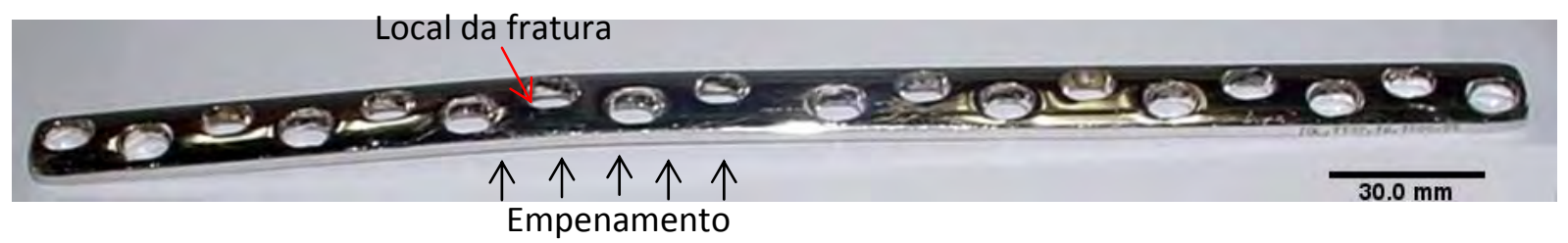

Figura 2. Imagem da placa mostrando empenamento e o local da fratura.

A superfície fraturada foi removida através de corte mecânico e analisada em lupa de baixa magnificação como também em microscópio eletrônico de varredura (MEV), para identificar os micromecanismos de falha.

O material utilizado para fabricação da placa foi avaliado de acordo com a norma ABNT NBR ISO 5832-1. (2) Para tanto foram realizados ensaios de metalografia para análise de inclusões, fases e tamanho de grão - e análise química. A metalografia foi realizada perpendicularmente a seção de fratura. Para análise química foi retirada uma amostra próxima do local da fratura.

\section{RESULTADOS}

\subsection{Análise Visual}

Foi observado que nas interfaces entre os furos e os parafusos houve desgaste dos materiais, ocasionado pelo movimento relativo dos dois componentes e 0 
subsequente processo de corrosão-desgaste, conforme pode ser visto nas imagens da Figura 3.
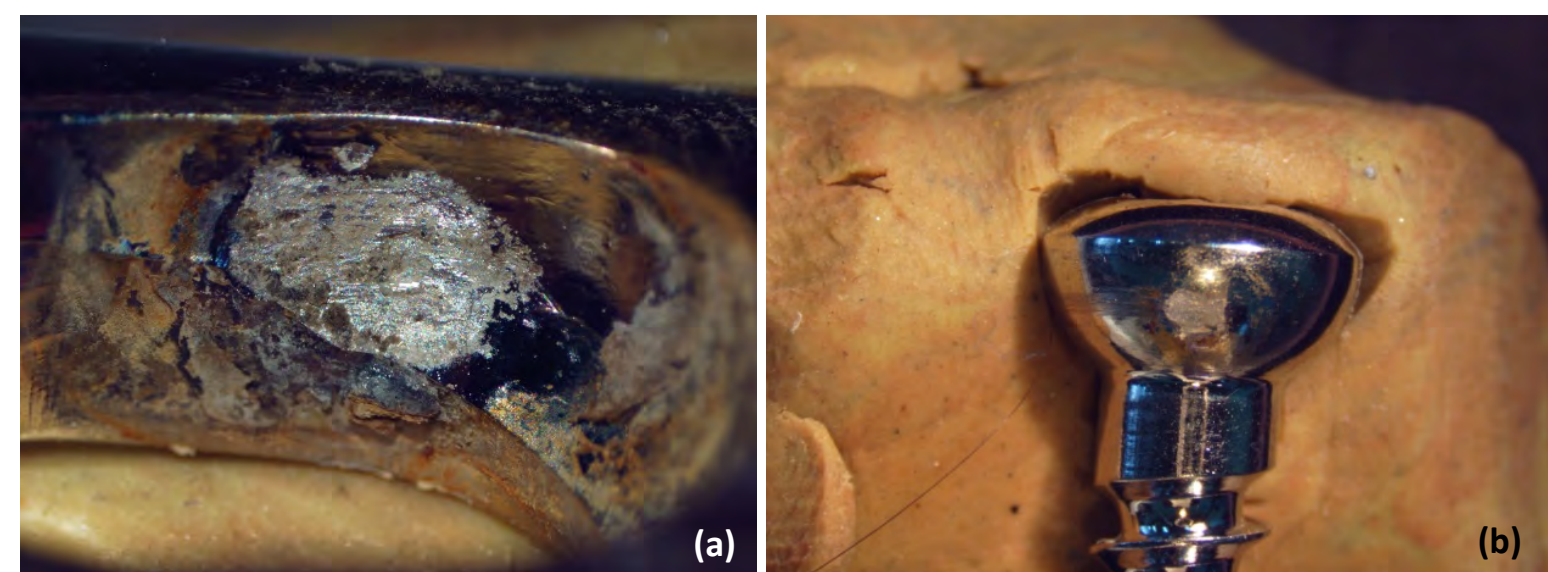

Figura 3. Imagens da superfície de contato entre um furo e um parafuso (a) furo da placa e (b) cabeça do parafuso.

\subsection{Análise da Superfície de Fratura}

Foi observado que a fratura se originou a partir da nucleação de uma trinca iniciada na região de contato entre um dos furos e o parafuso, como pode-se observar na Figura 4a. A Figura 4b mostra a superfície de fratura, após sua extração da placa por corte mecânico, onde foi possível determinar o ponto de início da ruptura, através das linhas radiais que apontam a nucleação da trinca.
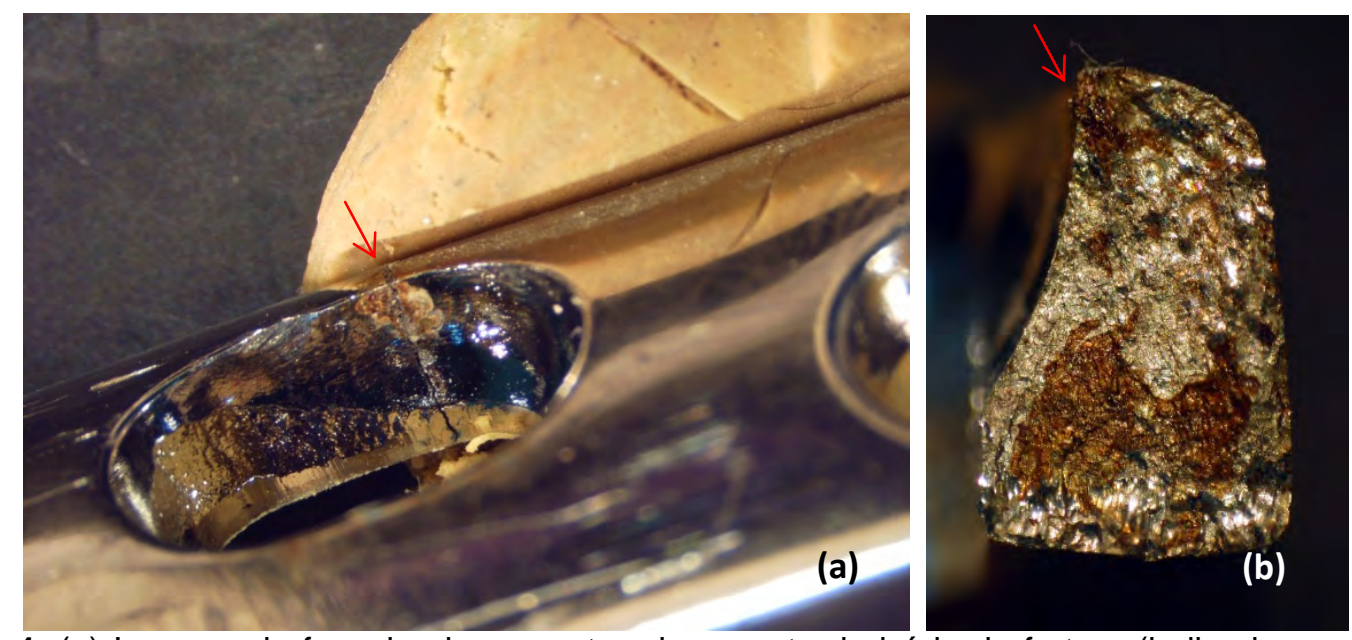

Figura 4. (a) Imagem do furo da placa mostrando o ponto de início da fratura (indicado por seta); e (b) Superfície de fratura mostrando ponto de início da trinca (indicado por seta).

\subsection{MEV}

$\mathrm{Na}$ análise em MEV foi possível observar microestrias de fadiga, conforme mostra a Figura 5, evidenciando que o componente rompeu por fadiga. 
$68^{\text {th }}$ abm international annual congress

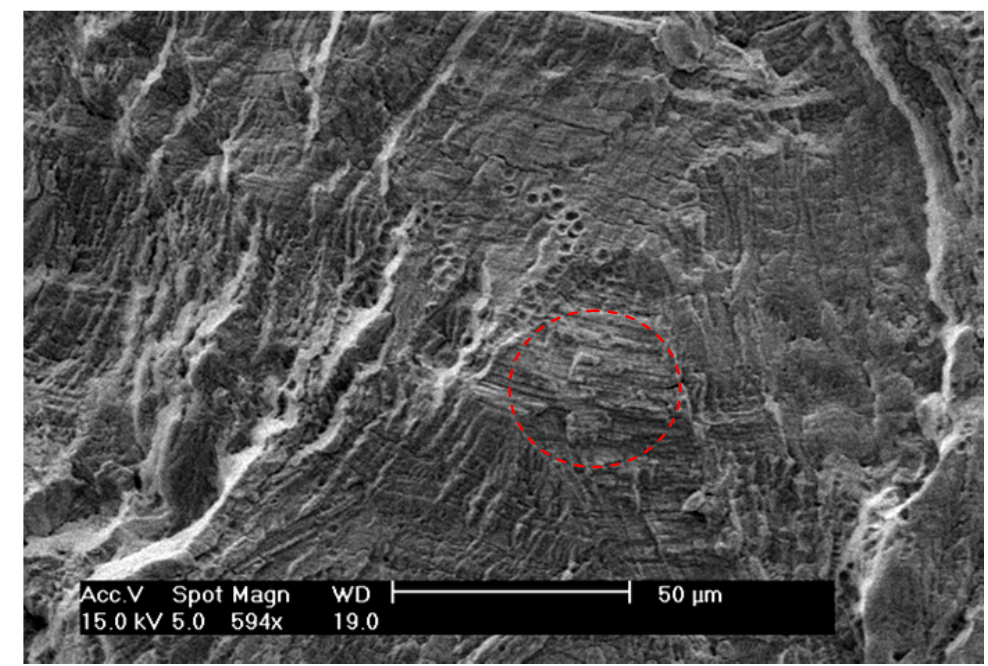

Figura 5. Fotomicrografia obtida em MEV da superfície de fratura da placa, mostrando uma das regiões com microestrias de fadiga.

\subsection{Análise Química}

A média dos resultados de três queimas, que forneceram a porcentagem em massa dos elementos presentes no aço inoxidável da placa, juntamente com a faixa determinada pela norma ABNT NBR ISO 5832-1 ${ }^{(2)}$ está mostrada na Tabela 1 para comparação.

Tabela 1. Resultados da análise química da placa

\begin{tabular}{c|c|c|c|c|c|c|c|c}
\hline \multicolumn{8}{c}{ COMPOSIÇÃO QUíMICA (\% EM MASSA) } \\
\hline & C & Si & Mn & P & S & Cr & Ni & Mo \\
\hline Amostra & 0,010 & 0,29 & 1,94 & 0,007 & 0,001 & 17,36 & 13,42 & 2,97 \\
\hline NBR ISO & 0,030 & 1,0 & 2,0 & 0,025 & 0,010 & $17,0-$ & $13,0-$ & $2,25-$ \\
$\mathbf{5 8 3 2 - 1}$ & máx. & máx. & máx. & máx. & máx. & 19,0 & 15,0 & 3,5 \\
\hline
\end{tabular}

\subsection{Metalografia}

As imagens mostradas na Figura 6 mostram a metalografia obtida na seção perpendicular à superfície de fratura. Através das imagens é possível observar trincas características de corrosão sob tensão e microestrutura típica de aço inox austenítico com grãos equiaxiais levemente deformados.
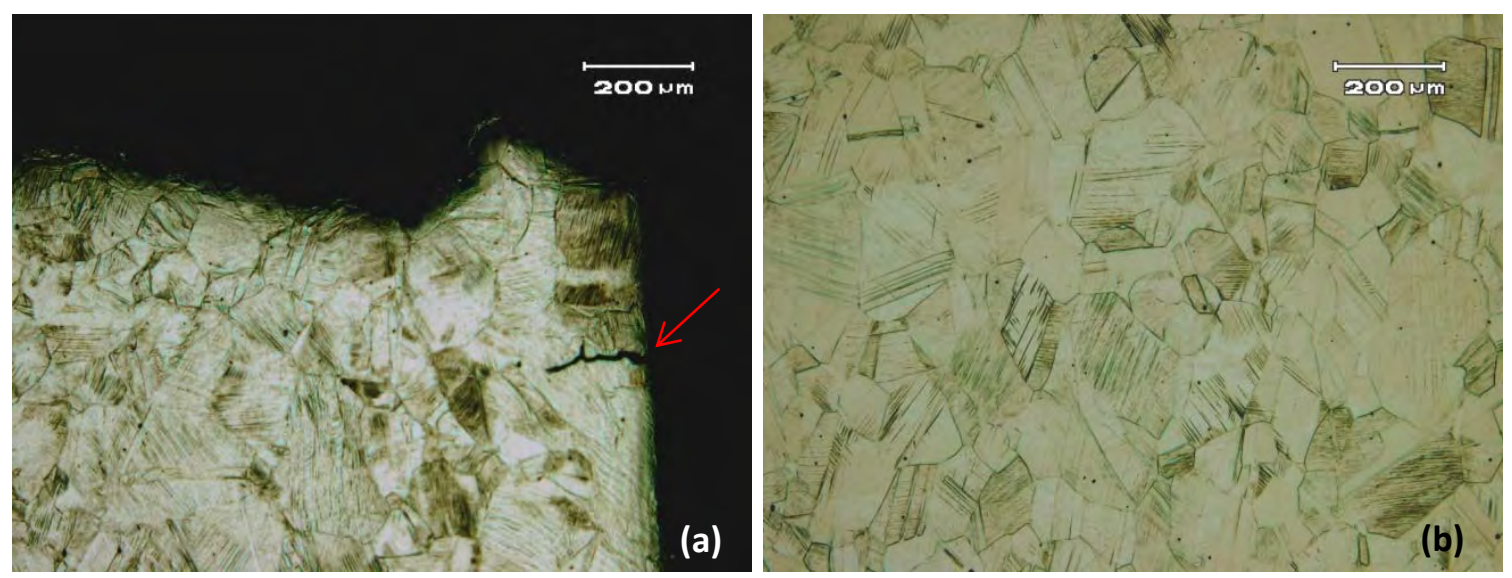

Figura 6. (a) Imagem micrográfica do ponto de início da fratura na placa mostrando uma trinca de corrosão sob tensão (indicado por seta); (b) Imagem mostrando a microestrutura do núcleo da placa, típica de aço inoxidável austenítico. 
Os grãos austeníticos foram medidos, segundo a técnica de intersecção linear descrita na norma ASTM E112. ${ }^{(3)}$ A norma NBR ISO 5832-1 ${ }^{(2)}$ admite um tamanho mínimo de 5 ASTM, isto é, não admite valores abaixo de 5 , que significam que o material tem grão mais grosseiro. A medição de grão para a amostra mostrou um tamanho de grão de 3,5 ASTM, ou seja, mais grosseiro do que o permitido pela norma.

\section{DISCUSSÃO}

De acordo com Davis, ${ }^{(1)}$ os implantes ortopédicos são expostos às forças bioquímicas e biomecânicas do corpo, e certas interações são relevantes entre os implantes e o ambiente biológico. $\mathrm{O}$ pH normal dos líquidos corporais é próximo ao neutro, porém regiões feridas apresentam pH ácido de cerca de 5,2; em um hematoma, pode ser de 4,0. No caso de infecções, o pH assume valores alcalinos.

No ponto onde ocorre corrosão por fricção, o ambiente pode se tornar ácido, devido aos produtos de corrosão, aumentando a chance de corrosão local.

Além disso, vários tipos de forças agem nos implantes e nos ossos. Em um sistema musculoesqueletal intacto, as forças atuantes estão balanceadas. Quando o osso fratura, o balanço de forças é desfeito e as forças musculares puxam os fragmentos em várias direções. ${ }^{(1)}$

Entretanto, se o osso apresenta pequenos vazios na fratura ou se fragmentos estão faltando, as forças de carregamento do peso do paciente não estarão completamente balanceadas e distribuídas. Como resultado, tensões podem concentrar em áreas do implante onde o suporte do osso não está presente. Sob a carga do peso do paciente, o implante recebe carga cíclica nessas regiões e um risco potencial de dano por fadiga pode estar presente. ${ }^{(1)}$

Quanto ao tipo de corrosão observada, fica claro que pode se tratar de uma corrosão por fricção, que conforme estabelece Dieter, ${ }^{(4)}$ acontece quando duas superfícies em contato experimentam um pequeno movimento relativo, de onde se origina um defeito superficial denominado dano por fricção. As trincas de fadiga quase sempre se iniciam na superfície danificada, embora possam ser ocultadas pelos detritos de óxido. Os danos de fricção são causados por uma combinação de efeitos mecânicos e químicos.

Outros autores como Antunes e Oliveira, ${ }^{(5)}$ explicam que a fricção exerce grande influência no comportamento em corrosão dos implantes ortopédicos devido aos efeitos potencialmente prejudiciais que ela exerce na estabilidade mecânica dos filmes passivos, que é o mecanismo de proteção contra corrosão dos aços inoxidáveis.

Conforme Dieter, ${ }^{(4)}$ quando o ataque corrosivo ocorre simultaneamente com o carregamento em fadiga, há uma redução significativa das propriedades em fadiga. Isso decorre do fato que o ataque químico acelera muito a taxa de propagação das trincas em fadiga. Os materiais que apresentam um limite de fadiga definido quando ensaiados ao ar e na temperatura ambiente, não apresentam indicação do limite de fadiga quando expostos a um meio corrosivo.

Não existem métodos de prevenção contra o dano por fricção que sejam completamente satisfatórios. No entanto, ele não ocorrerá se o movimento relativo puder ser eliminado ou reduzido. No caso de estudo, se o aperto entre os parafusos e a placa fossem adequados, não haveria uma taxa de desgaste tão intensa.

Embora o material do qual é fabricada a placa tenha composição química satisfatória, do ponto de vista da norma ABNT NBR ISO $5832-1^{(2)}$ se nota uma 
inconformidade quanto ao tamanho de grão medido, que é maior que o estabelecido pela norma citada. O tamanho de grão é um fator de influência nas propriedades de fadiga, pois uma estrutura de grãos refinados aumenta o limite de resistência à fadiga dos metais, conforme explicam Robinson e Beevers. ${ }^{(6)}$

O empenamento observado na placa também pode ter contribuído para a nucleação de uma trinca de fadiga, uma vez que o ponto de início de fratura coincide com a região deformada.

\section{CONCLUSÃO}

A placa rompeu por fadiga tendo como fonte nucleadora da trinca as marcas de corrosão-desgaste provocadas pelo movimento relativo entre a placa e o parafuso. O tamanho de grão grosseiro e o empenamento da placa podem ter reduzido a resistência à fadiga do material, contribuindo para a ruptura prematura da placa.

\section{Agradecimentos}

Aos financiadores, CNPq, FINEP, que forneceram recursos para a realização dos ensaios.

\section{REFERÊNCIAS}

1 DAVIS, J.R. ASM International ${ }^{\circledR}$, Handbook of Materials for Medical Devices, 2003.

2 ABNT NBR ISO 5832-1:08. Implantes cirúrgicos - Materiais metálicos. Parte 1: Aço inoxidável conformado.

3 ASTM E112-10. Standard Test Methods for Determining Average Grain Size.

4 DIETER, George E., Metalurgia Mecânica, $2^{\mathrm{a}}$ ed., Rio de Janeiro: Guanabara Dois, 1981.

5 ANTUNES, R. A. e OLIVEIRA, M. C. L. de, Corrosion fatigue of biomedical metallic alloys: Mechanisms and mitigation, Acta Biomateralia, Elsevier, 2012. Disponível em: $<$ www.elsevier.com/locate/actabiomat>.

6 ROBINSON, J. L. e BEEVERS, C. J., Metal Science, 1073, 7, p. 153. 